Article

\title{
Applying Lean Healthcare to Improve the Discharge Process in a Mexican Academic Medical Center
}

\author{
Rodrigo E. Peimbert-García ${ }^{1,2, * \mathbb{D}}$, Luis Meave Gutiérrez-Mendoza ${ }^{3}$ and Heriberto García-Reyes ${ }^{2}$ (D) \\ 1 School of Engineering, Macquarie University, Sydney, NSW 2109, Australia \\ 2 School of Engineering and Sciences, Tecnologico de Monterrey, Monterrey 64849, NL, Mexico; \\ heriberto.garcia@tec.mx \\ 3 Department of Public Health, Faculty of Medicine, Universidad Autónoma de San Luis Potosí, \\ San Luis Potosí 78300, SLP, Mexico; luismeave@hotmail.com \\ * Correspondence: rodrigo.peimbert@tec.mx; Tel.: +61-42-346-7860
}

\section{check for}

updates

Citation: Peimbert-García, R.E.; Gutiérrez-Mendoza, L.M.;

García-Reyes, H. Applying Lean

Healthcare to Improve the Discharge

Process in a Mexican Academic

Medical Center. Sustainability 2021,

13, 10911. https://doi.org/10.3390/ su131910911

Academic Editors: María del

Mar Espinosa Escudero and

Manuel Domínguez

Received: 27 June 2021

Accepted: 2 August 2021

Published: 30 September 2021

Publisher's Note: MDPI stays neutral with regard to jurisdictional claims in published maps and institutional affiliations.

Copyright: (c) 2021 by the authors. Licensee MDPI, Basel, Switzerland. This article is an open access article distributed under the terms and conditions of the Creative Commons Attribution (CC BY) license (https:// creativecommons.org/licenses/by/ $4.0 /)$.
Abstract: Lean Thinking has been one of the preferred approaches to improve healthcare processes in developed countries; however, it has been barely used in Latin America. This study presents a Lean implementation in a Mexican public academic medical center. The goal was to reduce the time required to discharge patients from the Internal Medicine Department. This non-experimental intervention study measured, analyzed, and improved the process flow through a time study, valueadded/non-value-added analysis, and the four-step quick changeover approach. Once changes were implemented, inferential statistics were used to compare results. Lean implementation allowed reducing the time to discharge patients from 6 to $3 \mathrm{~h}$ by eliminating $57 \%$ of non-value-added activities and $70 \%$ of errors found in discharge orders. This represents a $2 \%$ annual capacity increase and a $6.423 \mathrm{~h}$ bed made available without investment. Other findings include barriers regarding untrained staff about process improvement and departmental barriers and a successful quick changeover implementation. This is one of the handful of implementations of Lean Healthcare in Latin America. Furthermore, this is one of the very first studies that showcase the implementation of the quick changeover approach in healthcare. Further research should focus on the long-term impact and how the specific environment encourages/discourages future implementations.

Keywords: Lean; healthcare; hospital; internal medicine; SMED; quick changeover; Mexico

\section{Introduction}

Nowadays, there is an increasing demand for healthcare services that creates challenges for hospitals in terms of cost and efficiency. Thus, healthcare professionals in many countries around the world are struggling to provide competent and safe care while being pushed to optimize the use of resources [1]. Such is the case of hospitals in Mexico, where many healthcare processes are characterized by inefficiencies and significant levels of waste. In central-north Mexico, the Internal Medicine Department of a large public academic medical center has been facing different challenges related to wasteful activities, long admissions, lengths of stay, and discharges, and general delays that can result in overcrowding, a long waiting list, and patient dissatisfaction.

One of the common approaches to reach hospital efficiency and provide better quality of care has been Lean Thinking. This is because Lean can change how hospitals conduct their operations as it allows one to improve the quality of care, reduce errors and waiting times, support employees, and eliminate departmental barriers [2,3]. However, even when journal-based literature shows a wide application of Lean in healthcare settings in developed countries, the evidence of applications in Latin America is scarce [4], with a couple of studies carried out in Brazil [5,6], Mexico [7], and the Internal Medicine Department in Colombia [8]. 
Specific to this last department, few studies have reported on the use of Lean, with a focus on reducing either the outpatient lead time [8], patient length of stay [9], or waiting time between activities [10], among others. Here, one of the processes that is often characterized by significant delays, due to non-added-value activities, is patient discharge. This is one of the main concerns in the Mexican medical center under study as it takes an excessive amount of time (an average of $6 \mathrm{~h}$ ) to discharge a patient. Since some studies have previously identified similar opportunities in other countries (the United States [1], Netherlands [11], Jordan [12], and India [13,14], etc.), and others have provided evidence of relevant improvements $[15,16]$, the purpose of this research study was to conduct a Lean Healthcare project to analyze and improve (reduce) the time to discharge patients from the Internal Medicine Department of a Mexican public academic medical center.

The remainder of the paper is organized as follows: the relevant literature review is presented in Section 2, followed by the materials and methods presented in Section 3. While Section 4 presents the analysis and results, Section 5 presents a detailed discussion of the results and their connection with the current literature. Finally, Section 6 presents the conclusions that address the managerial implications, contributions, limitations, and insights for future research.

\section{Literature Review}

There are several indicators used to measure healthcare performance, such as waiting time (to see a physician, receive the required treatment, or triage), number of patients left without being seen, and length of stay (LOS), among others [17]. One of the improvement approaches to mitigate the financial (and possibly clinical) impact of these is Lean Thinking, which is defined as a management philosophy and improvement approach to create value for customers by using fewer resources and eliminating different sources of waste [18]. Even though Lean has been commonly related to manufacturing processes, it has been appealing to healthcare organizations around the globe since the early 2000s [19]. Since it focuses on the patient as the centerpiece throughout the process, the concept of "Lean Healthcare" has gained more relevance every year. Nowadays, it is possible to identify more than 40 concepts, tools, or methodologies related to Lean within the healthcare context [20].

Literature shows how these Lean concepts and tools have been used to improve healthcare operations [21] and assess the impact on patient care [17]. One critical process within healthcare operations that has a large impact on patient care is the discharge process, which is defined as the group of activities involving the patient and staff members (from several disciplines and departments) that work together to allow the patient to leave the healthcare facility [22]. The reduction of the time required to conduct this group of activities is critical to increasing efficiency and the quality of care, as previous research has shown [23]. When the patient is approved to discharge, he/she is not willing to stay in the hospital any longer, and thus any delay creates the patient's discontent, which in turn can affect the reputation of the healthcare institution [22].

The discharge process seems to be effectively managed by improving key procedures that assure better compliance with the discharge plan $[11,13,24]$. Lean allows for this, but its adoption is not a trivial journey; expert support (internal or external) regarding process improvement is required. Parallelly, people and expectations should also be carefully managed, as it is not uncommon to face barriers and challenges such as: lack of management support, lack of knowledge and understanding, lack of cooperation between groups, previous negative experiences with similar attempts, lack of standardization, and slow adoption of new interventions, among others $[17,21]$.

In order to reach the full benefits of Lean in the long term, it should be aligned with the organizational strategy and embedded into the work culture. Here, the right leadership style is a key component to both promote a top-down commitment and enable the professional autonomy required to adopt Lean [25]. This should also allow building an adequate team to run the pilot project and providing them with the right training and 
tools. An effective technique derived from Lean that has been barely used, and possibly undervalued in the healthcare context, is the quick changeover approach [26]. This allows reducing delays, waiting times, and, overall, limiting the time and effort required to conduct a specific process [27]. Although this approach has proven to be highly effective in manufacturing environments, future research should consider its application within the healthcare context [26]. This research study focused, then, on using this approach to reduce the time required to discharge patients from the Internal Medicine Department.

\section{Materials and Methods}

This non-experimental intervention study sought to implement Lean to reduce the time required to discharge patients from the Internal Medicine Department. This process has been identified as one of the lengthy processes in the department and the overall hospital. The setting was a 250-bed public academic medical center located in central-north Mexico. The general approach is presented throughout three stages: (1) discharge process diagnosis, (2) time studies and data collection through shadowing staff members and measuring the percentage of discharge orders (DOs) with errors, and (3) implementing the Lean approach known as quick changeover. After the intervention, the discharge time was measured again to compare the results and validate a statistical improvement through a two-sample hypothesis testing. Given that this study did not collect clinical data regarding human subjects, an exemption from review by Institutional Review Board was possible.

The general information about the process was provided by the Quality Department. Meanwhile, samples related to discharge times (before and after the intervention) were collected first-hand using a chronometer in February and September of 2019. These times were documented in minutes and seconds and later converted to decimal. Two-people teams were exclusively assigned to follow DOs during $100 \%$ of the data collection time. Thus, if there were inaccuracies in the data collected, they are assumed to be very small and can be neglected.

The quick changeover approach, also known as the single-minute exchange of die (SMED), was selected as it aims at increasing productivity by reducing waiting times and unused human talent, e.g., surgeons waiting for the next patient in the operating room [27]. A common non-healthcare example of this is pit crews at a NASCAR race. The overall goal is to limit the time/effort needed to conduct a process/event. In a healthcare process, three types of activities are identified when using the quick changeover approach [18]:

- Value-added external activities that can take place anytime but should occur before or after the process;

- Value-added internal activities that occur during the process and should be made external when possible;

- Non-value-added or waste activities that should be eliminated (or at least reduced).

After the process diagnosis and data collection, the quick changeover approach is conducted through the following conceptual stages represented in Figure 1 [28]:

1. Identifying and separating internal, external, and wasteful activities.

2. Eliminating wasteful activities.

3. Converting internal to external activities.

4. Streamlining all aspects of the process.

The project, including the time study, value-added vs. non-value-added analysis, defective DO count, and quick changeover implementation, was carried out by a team of external consultants. With respect to the statistical validation of results, a goodnessof-fit test was conducted for normality in each data set, and consequently, a parametric or non-parametric test was performed to compare both samples of times, before and after the intervention. 
(1)

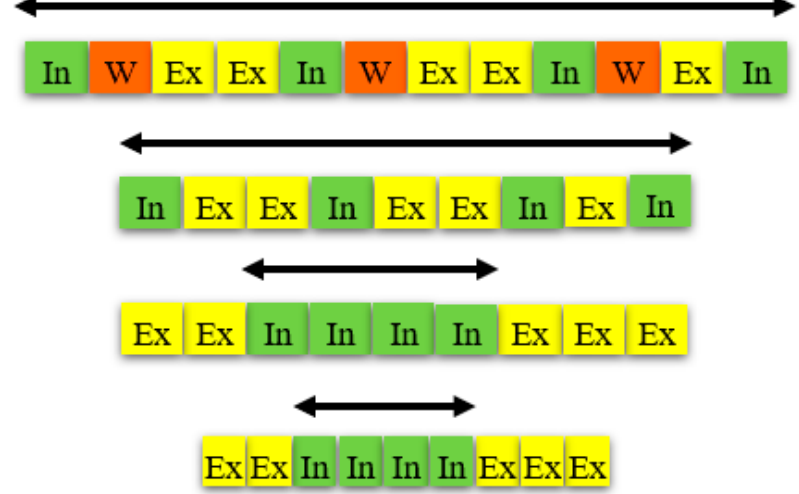

Figure 1. Quick changeover application sequence.

\section{Results}

The study was conducted by a team of external consultants led by a Lean Six Sigma Master Black Belt. The healthcare staff had no previous experience in the use of Lean tools, but they managed to provide the information and support needed to conduct the project. As a result, the analysis and findings are presented through three sub-sections: diagnostic, time studies and data analysis, and process improvement.

\subsection{Diagnostic}

The process starts in the morning when a physician gives a verbal order to residents and nursing staff that a patient is ready to go and ends when this patient leaves the hospital, usually during the afternoon. First, a process flow diagram revealed that DOs go through the following sequence:

1. Physicians, including residents, interns, and externs (third-year medical students).

2. Nursing.

3. Pharmacy.

4. Social workers.

5. Medicine department (MD) validators who check the coverage according to the public medical insurance called "seguro popular".

6. Financial support (if needed).

7. Cash desk.

8. Security

The layout indicated that most departments, except cash desk and security, were located in physical areas next to each other. Additionally, there were two working shifts with an unbalanced staff distribution, which are shown in Table 1. Nonetheless, the labor union has imposed constraints related to working hours and schedules that limit the intervention from introducing changes in this regard.

\subsection{Analysis}

Once the process flow was clearly understood, the shadowing approach was used to measure the time that a DO stays at each step of the process. Figure 2 presents the progression of one randomly selected order that required $5 \mathrm{~h}$ and $20 \mathrm{~min}(5.33 \mathrm{~h}$ in decimal units). Value-added activities (green boxes) add up to $41 \%$ of the total time, and wastes due to transport (blue) and waiting (red) together represent $59 \%$ of the total time. The average total time required by all orders was $5.95 \mathrm{~h}$, with a standard deviation of $2.9 \mathrm{~h}$. Meanwhile, the average percentage of time due to non-value-added activities was $57 \%$. The longest waiting times are due to correcting errors in DOs and the prescription. 
Table 1. Staff distribution per shift.

\begin{tabular}{cccc}
\hline \multirow{2}{*}{ Area } & Total Staff Members & \multicolumn{2}{c}{ Staff Members per Shift } \\
\cline { 3 - 4 } & 7 & First: 7 a.m.-2 p.m. & Second: 2 p.m.-9 p.m. \\
\hline Interns & 30 & 5 & 2 \\
Externs & 7 & 27 & 3 \\
Residents & 11 & 6 & 2 \\
Nursing (men) & 6 & 3 & 5 \\
Nursing (women) & 2 & 1 & 3 \\
Social Workers & 3 & 2 & 1 \\
Pharmacy & 3 & 1 & $2^{1}$ \\
MD Validators & 4 & $3^{1}$ & $1^{1}$ \\
Cash Desk & 4 & &
\end{tabular}

${ }^{1}$ Staff members who provide support to the entire hospital.

$\%$ of Avg. Value-Added Time (green)= $131.8 \mathrm{~min} .41 \%$

$\%$ of Avg. Non-Value-Added Time (red + blue) $=188.5 \mathrm{~min} .59 \%$

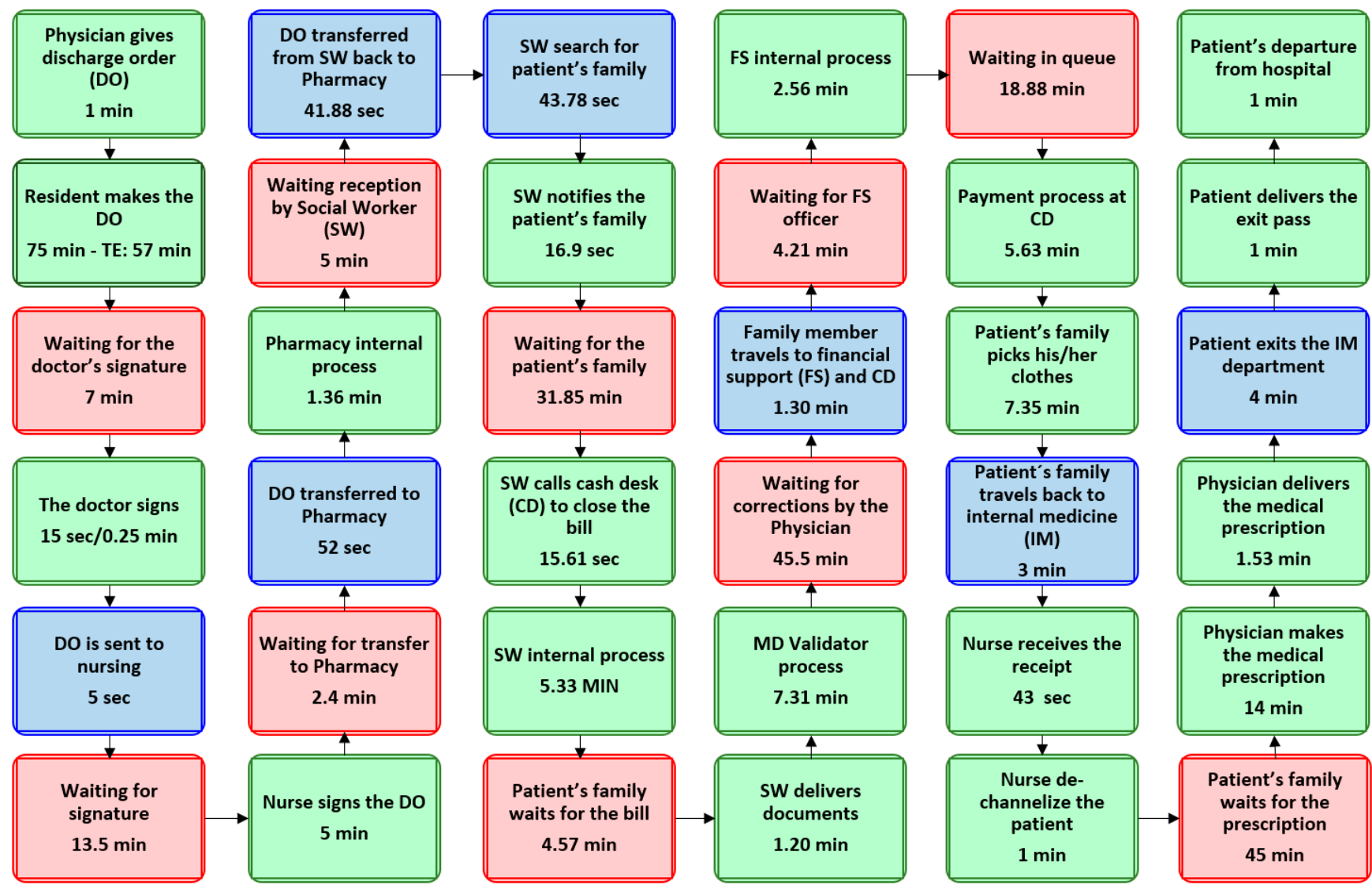

Figure 2. Example of shadowing one discharge order randomly selected.

On the other hand, Figure 3 illustrates the distribution of the average total time required to discharge patients across all departments, considering value-added and nonvalue-added activities.

The analysis also showed that $70 \%$ of the sampled DOs presented errors, and a Pareto analysis indicated that date, diagnostic, and condition description together represented $60 \%$ of total errors. This occurs because physicians have difficulties in managing the terminology required (in DOs) by public health insurances covering patients' expenses. Thus, MD validators sent defective DOs back to physicians at the time when they are usually engaged in other activities and physical locations. Once DOs are corrected by physicians and approved by MD validators, family members can proceed to pay at the cash 
desk, usually after 2:00 p.m. Due to the high variability in the process, family members are seldom available at the time, and thus waiting time is added. Meanwhile, as Table 1 shows, the cash desk during the afternoon has only one-third of the installed capacity available during the morning, which results in a bottleneck. Finally, the patient still has to wait for a physician to write the medical prescription.

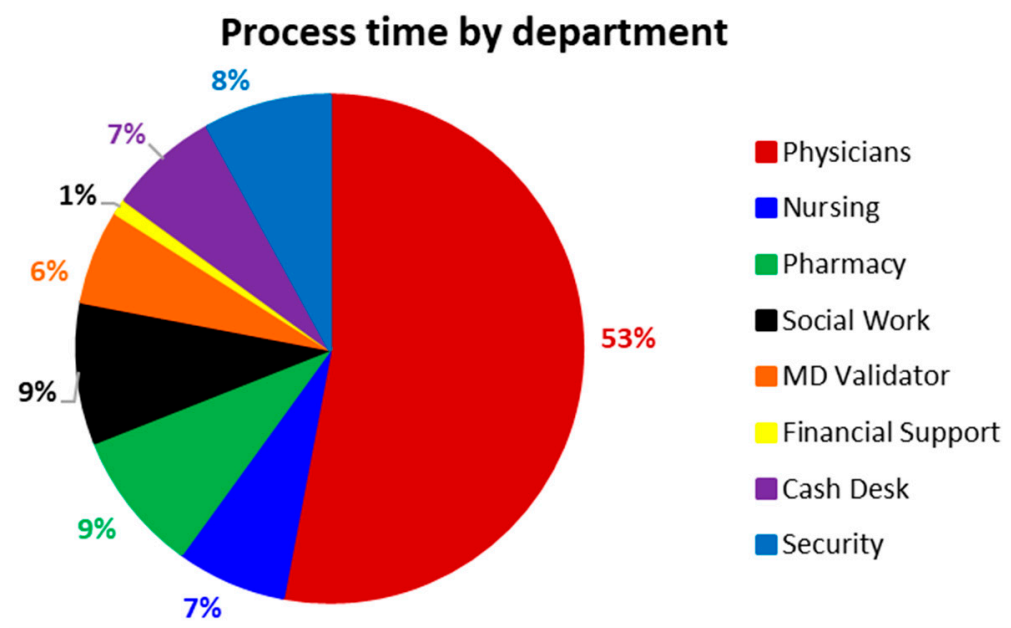

Figure 3. Distribution of the discharge time by department.

\subsection{Improvement}

The proposed implementation of the quick changeover was found to be suitable for this research. The "as-is" process is presented on the left side of Figure 4. The sequential process is described through the four steps presented in Figure 1 (Methods):

1. Identifying and separating internal, external, and wasteful activities: While Figure 2 showed wasteful activities across the process, these are summarized as red boxes in Figure 4. Additionally, each block of consecutive activities is classified as internal or external activities (green boxes).

2. Eliminating wasteful activities: The main wastes are associated with the physician throughout the entire process. While the main concerns are the large number of errors found in DOs, their correction, and the long waiting times for the prescription, these also have an impact on the other sources of waste in a systemic way. These are reduced in the following step.

3. Converting internal to external activities: Two key activities that are carried out during the process (internal) should occur before (external): pre-filling the DO, ideally the day before, and its pre-evaluation and fix by the MD validator early in the morning (first two dotted lines). This will reduce the number of defective orders, as well as the corresponding waiting times.

4. Streamlining all aspects of the process: The prescription can be provided at the beginning of the process, along with the DO (third dotted line). This and the previous changes (step 3) eliminate rework and reduce waiting times, given that physicians and family members are still around during the morning (when required), and the cash desk is reached during the first working shift.

The improved process is shown on the right side of Figure 4. Shadowing was conducted again to collect data after implementation, and the average time to discharge patients was found to be $3.07 \mathrm{~h}$. The second sample did not follow a normal distribution, and thus the two-sample Mann-Whitney test was performed to show the new average discharge time is statistically smaller $(p$-value $=0.024)$. 


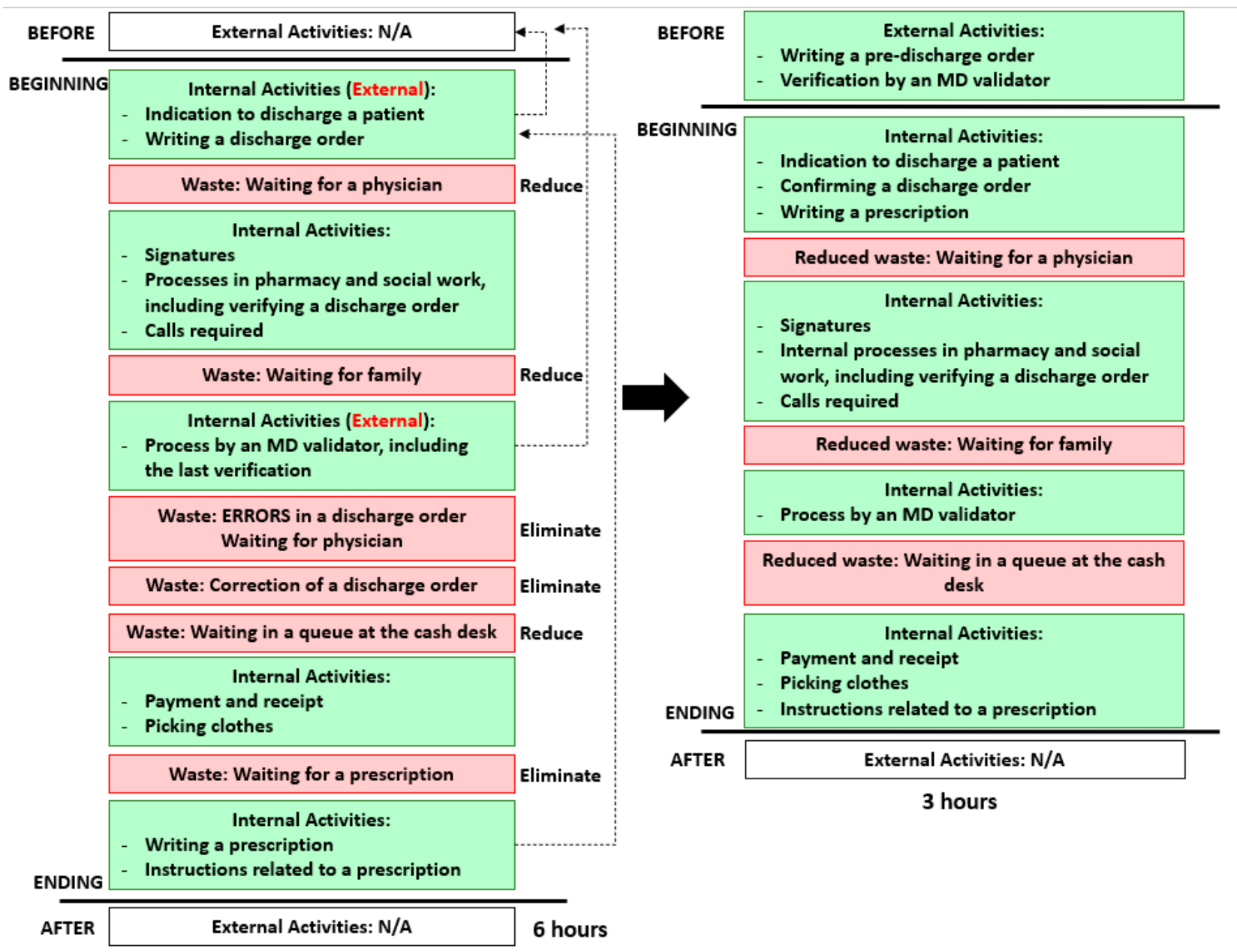

Figure 4. Quick changeover analysis before and after the implementation.

\section{Discussion}

Patient discharge is a very lengthy process where delays increase the overall cost for the hospital and the patient's exposure to acquiring new infections [22]. Yet, changes in the discharge timing are arguably one of the least disruptive ways to improve efficiency [16]. Such was the case presented in this article, where the time required to discharge patients was found to be around $6 \mathrm{~h}$ and later reduced without creating interruptions. Similar to what has been reported before in a general ward in Boston [23] and the Internal Medicine Department in Montreal [29], significant variability was identified in how the process is carried out and the preparation of the discharge prescription, having a direct impact on the time of discharge. This is mainly because the discharge order was filled during the morning on the day of discharge, and the prescription was filled and attached at the very end of the process (Figure 2). However, some authors have stated that the morning hours are unsuitable for the kind of processes and, ideally, this preparation should occur the day before discharge, when the patient has been identified (tentatively) as ready to leave the next day $[15,16]$. This early identification should trigger some final activities such as the review of test results, nurse education, writing discharge orders, medication reconciliation, and the completion of paperwork [15]. Along with attaching the prescription during the morning, these changes enabled the Internal Medicine Department to become more efficient: First, they foster MD validators to detect errors before the discharge process starts; second, they reduce/eliminate waiting times, as the process is carried out in a shorter period when physicians and family members are still around; and third, they allow physicians and residents to be involved in other activities in different departments without the need to go back to Internal Medicine. 
With the changes in place, the discharge time was reduced to approx. $3 \mathrm{~h}(p$-value $=0.024)$, which can be translated into both a $2 \%$ annual capacity increase and a $6.423 \mathrm{~h}$ bed available for the medical center (133.8 yearly hours per bed $\times 48$ beds). These findings are consistent with previous results, from different healthcare departments, that have been published in the literature, e.g., the $15 \%$ reduction in the average discharge time, from 3.3 to $2.8 \mathrm{~h}$, in a medical and surgical department [30], and the 39\% reduction, from approx. 4 to $2.5 \mathrm{~h}$, in a hospital in India [14]. Nevertheless, this study resulted in one of the most significant improvements regarding the discharge of patients, with a reduction of almost $3 \mathrm{~h}(173 \mathrm{~min})$, which represents $48 \%$ of the total time prior to the intervention.

These results were achieved by considering and including some well-documented factors for success, such as leadership and support from the top-level executives, customer (patient) focus, external expert guidance, constant communication with the team and staff, project selection with a realistic scope, and data collection using well-defined metrics [31,32]. Additionally, even when healthcare services provided in Mexico and Latin American countries do not always meet the standards of more developed economies, staff members try to serve their patients in a timely manner [6]. Hence, the personnel from the Internal Medicine had an open and receptive attitude and were willing to help during the intervention, regardless of their lack of knowledge and experience using Lean. Since the head of the department was very interested and provided the required support, the intervention also allowed to break down some communication barriers between functional areas within the department. A focus on improving the experience of the patient gave staff members a sense of a greater good and then created a positive attitude toward cooperating with the external team.

Although people understand and appreciate the benefits of using Lean and the quick changeover approach for process improvement, it has been noted that staff members require time and training to make significant improvements, in a way that prevents them from wanting to retreat to an earlier period, when they did not have any domain of responsibility to improve existing processes [16]. Thus, given that they did not receive any internal or external training regarding systematic process improvement, a quality improvement program for internal medicine residents and front-line workers would be a strategic way to provide specialized training (and patient safety). Literature already provides evidence of this kind of initiative in the U.S., particularly Michigan, where a residency program's educational curriculum was developed, including a team-based project, for all trainees in the internal medicine department [33]. Another similar initiative that can serve as a reference is the one developed in Boston, where internal medicine residents work in teams to learn the necessary skills to plan and conduct an improvement project using the Lean approach [34].

\section{Conclusions}

This paper presented a successful implementation of the quick changeover approach to the healthcare context. This intervention resulted in the reduction of the discharge time from 6 to $3 \mathrm{~h}$, which can be translated into a $\%$ annual capacity increase for the public medical center without any additional investment. While this was a small process compared to the size of the hospital, some authors have pointed out that small wins should be used to increase momentum and anchor changes. For this public institution, this is the first win toward becoming a Lean healthcare organization that seeks to improve the quality of care of Mexican citizens.

Now, top management is aware that hospital processes can be subject to significant improvements with very specific interventions; however, leaders also realize they need expert support to achieve this. The next step, then, should be to seek ways to access this expertise in a cost-effective way. In particular, the head of department should make sure the new process is institutionalized across all areas that participate in the discharge process. Among other activities, this may include a sensitivity training, as well as including some quality improvement teachings, as developed by some authors [33,34]. 
As noted by Henrique and Filho [26], the quick changeover is one of the scarcely used approaches in healthcare. Thus, the main contribution of this article is the showcase of how the quick changeover approach is implemented in the healthcare context. Furthermore, there is a level of novelty in how the approach is adapted to a people-focused process rather than a machine-based one, as it is commonly conceived [6]. Similarly, there is just a handful of Lean Healthcare cases that have been documented in Latin America. This study represents one of the very few Lean Healthcare initiatives conducted in Mexico and Latin America that have been documented in peer-reviewed journals.

One limitation of this study lies in that some factors related to internal staff, such as assembling a team, training, and engagement, were not considered in this external intervention. This may jeopardize the long-term effect of this intervention, as long-term success heavily depends on the extent to which management and staff members understand and are committed to the change [35]. This represents the second limitation; the sustainability aspect is not part of this research work but a future one. Lastly, the union constraint resulting in unbalanced work teams (without apparent reason) must be considered to take advantage of this initial effort. Negotiation and involvement of union members may be required for further improvement interventions.

Future research should focus on extending this study and focusing on the sustainability of the intervention in the Internal Medicine Department, given that very little evidence exists that demonstrates the sustainability of Lean efforts in healthcare [19,36]. Moreover, other interventions in different healthcare departments should be considered. Afterward, if positive long-term effects are not achieved, further research should focus on analyzing and understanding the factors that prevent Lean to be successfully implemented, taking into consideration the specific leadership, work environment, and organizational culture. Overall, more studies around Lean implementations in healthcare should be conducted and documented in Mexico and probably Latin America. Ultimately, the goal in Lean healthcare is not just about the efficiency but also the quality of care and, consequently, the quality of life.

Author Contributions: Conceptualization, R.E.P.-G.; methodology, R.E.P.-G.; validation, R.E.P.-G. and L.M.G.-M.; formal analysis, R.E.P.-G.; investigation, R.E.P.-G. and H.G.-R.; resources, R.E.P.G.; data curation, R.E.P.-G.; writing-original draft preparation, R.E.P.-G., L.M.G.-M. and H.G.-R.; writing-review and editing, R.E.P.-G., L.M.G.-M. and H.G.-R.; project administration, R.E.P.-G. All authors have read and agreed to the published version of the manuscript.

Funding: This research received no external funding.

Institutional Review Board Statement: Ethical review and approval were waived for this study, given that it did not collect any data regarding human or animal subjects.

Informed Consent Statement: Not applicable.

Data Availability Statement: The data related to the two samples (times) collected are available upon request.

Conflicts of Interest: The authors declare no conflict of interest.

\section{References}

1. Brackett, T.; Comer, L.; Whichello, R. Do Lean Practices Lead to More Time at the Bedside? J. Healthc. Qual. 2013, 35, 7-14. [CrossRef]

2. Graban, M. Lean Hospitals: Improving Quality, Patient Safety, and Employee Engagement, 3rd ed.; CRC Press: Boca Raton, FL, USA, 2016.

3. Costa, L.B.M.; Folho, M.G. Lean healthcare: Review, classification and analysis of literature. Prod. Plan. Control 2016, 27, 823-836. [CrossRef]

4. Peimbert-García, R.E.; Matis, T.; Cuevas-Ortuño, J.; Nucamendi-Guillen, S.M. Systematic Review of Literature on Lean and Six Sigma in Healthcare and Directions for Future Research. In Proceedings of the 10th International Conference on Industrial Engineering and Operations Management (IEOM), Dubai, United Arab Emirates, 10-12 March 2020.

5. Da Silva, I.B.; Seraphim, E.C.; Agostinho, O.L.; Lima, J.O.F.; Batalha, G.F. Lean office in health organization in the Brazilian Army. Int. J. Lean Six Sigma 2015, 6, 2-16. [CrossRef] 
6. Godinho Filho, M.G.; Boschi, A.; Rentes, A.F.; Thurer, M.; Bertani, T.M. Improving hospital performance by use of lean techniques: An action research project in Brazil. Qual. Eng. 2015, 27, 196-211. [CrossRef]

7. Peimbert-García, R.E.; Matis, T.; Beltran-Godoy, J.H.; Garay-Rondero, C.L.; Vicencio-Ortiz, J.C.; López-Soto, D. Assessing the state of lean and six sigma practices in healthcare in Mexico. Leadersh. Health Serv. 2019, 32, 644-662. [CrossRef]

8. Ortíz-Barrios, M.A.; Escorcia-Caballero, J.P.; Sánchez-Sánchez, F.; De Felice, F.; Petrillo, A. Efficiency Analysis of Integrated Public Hospital Networks in Outpatient Internal Medicine. J. Med. Syst. 2017, 41, 163. [CrossRef] [PubMed]

9. Van Leeuwen, K.C.; Does, R.J.M. Quality Quandaries: Lean Nursing. Qual. Eng. 2010, 23, 94-99. [CrossRef]

10. Fischman, D. Applying Lean Six Sigma methodologies to improve efficiency, timeliness of care, and quality of care in an internal medicine residency clinic. Qual. Manag. Health Care 2010, 19, 201-210. [CrossRef] [PubMed]

11. Niemeijer, G.C.; Trip, A.; Ahaus, K.T.; Does, R.J.; Wendt, K.W. Quality in trauma care: Improving the discharge procedure of patients by means of Lean Six Sigma. J. Trauma Acute Care Surg. 2010, 69, 614-619. [CrossRef] [PubMed]

12. El-Banna, M.A. Improving Patients Discharge Process in Hospitals by using Six Sigma Approach. World Acad. Sci. Eng. Technol. 2012, 6, 1378-1387.

13. Udayai, K.; Kumar, P. Implementing Six Sigma to improve hospital discharge process. Int. J. Pharm. Sci. Res. 2012, 3, 4528-4532. [CrossRef]

14. Vijay, S.A. Reducing and Optimizing the Cycle Time of Patients Discharge Process in a Hospital Using Six Sigma DMAIC Approach. Int. J. Qual. Res. 2014, 8, 169-182.

15. McDermott, C.M.; Venditti, F.J. Implementing lean in knowledge work: Implications from a study of the hospital discharge planning process. Oper. Manag. Res. 2015, 8, 118-130. [CrossRef]

16. Molla, M.; Warren, D.S.; Stewart, S.L.; Stocking, J.; Johl, H.; Sinigayan, V. A Lean Six Sigma Quality Improvement Project Improves Timeliness of Discharge from the Hospital. Jt. Comm. J. Qual. Patient Saf. 2018, 44, 401-412. [CrossRef] [PubMed]

17. Zepeda-Lugo, C.; Tlapa, D.; Baez-Lopez, Y.; Limon-Romero, J.; Ontiveros, S.; Perez-Sanchez, A.; Tortorella, G. Assessing the Impact of Lean Healthcare on Inpatient Care: A Systematic Review. Int. J. Environ. Res. Public Health 2020, 17, 5609. [CrossRef]

18. Womack, J.P.; Jones, D.T. Lean Thinking: Banish Waste and Create Wealth in Your Corporation, 2nd ed.; Free Press: New York, NY, USA, 2003.

19. Peimbert-García, R.E. Analysis and Evaluation of Reviews on Lean and Six Sigma in Healthcare. Qual. Manag. Health Care 2019, 28, 229-236. [CrossRef] [PubMed]

20. Senna, P.; Gomes, A.; Monteiro, A.; Pinha, D. Study on Techniques and Tools Used in Lean Healthcare Implementation: A Literature Review. Braz. J. Oper. Prod. Manag. 2016, 13, 406-420. [CrossRef]

21. Costa, L.B.; Filho, M.G.; Rentes, A.F.; Bertani, T.M.; Mardegan, R. Lean healthcare in developing countries: Evidence from Brazilian hospitals. Int. J. Health Plan. Manag. 2017, 32, 99-120. [CrossRef] [PubMed]

22. Hamid, S.; Jan, F.A.; Rashid, H.; Jalali, S. Study of hospital discharge process viz a viz prescribed NABH standards. Int. J. Contemp. Med. Res. 2018, 5, H1-H4. [CrossRef]

23. Chen, L.M.; Freitag, M.H.; Franco, M.; Sullivan, C.D.; Dickson, C.; Brancati, F.L. Natural history of late discharges from a general medical ward. J. Hosp. Med. 2009, 4, 226-233. [CrossRef]

24. Breslin, S.E.; Hamilton, K.M.; Paynter, J. Deployment of Lean Six Sigma in care coordination: An improved discharge process. Prof. Case Manag. 2014, 19, 77-83. [CrossRef]

25. Van Rossum, L.; Aij, K.H.; Simons, F.E.; van der Eng, N.; Ten Have, W.D. Lean healthcare from a change management perspective. J. Health Organ. Manag. 2016, 30, 475-493. [CrossRef]

26. Henrique, D.B.; Filho, M.G. A systematic literature review of empirical research in Lean and Six Sigma in healthcare. Total Qual. Manag. Bus. Excell. 2020, 31, 429-449. [CrossRef]

27. Gabow, P.A.; Goodman, P.L. The Lean Prescription: Powerful Medicine for Our Ailing Healthcare System; CRC Press: New York, NY, USA, 2014.

28. Dillon, A.P.; Shingo, S. A Revolution in Manufacturing: The SMED System; CRC Press: New York, NY, USA, 1985.

29. Meguerditchian, A.N.; Krotneva, S.; Reidel, K.; Huang, A.; Tamblyn, R. Medication reconciliation at admission and discharge: A time and motion study. BMC Health Serv. Res. 2013, 13, 1-11. [CrossRef]

30. Allen, T.T.; Tseng, S.H.; Swanson, K.; McClay, M.A. Improving the Hospital Discharge Process with Six Sigma Methods. Qual. Eng. 2009, 22, 13-20. [CrossRef]

31. Kim, C.S.; Spahlinger, D.A.; Kin, J.M.; Coffey, R.J.; Billi, J.E. Implementation of Lean Thinking: One Health System's Journey. Jt. Comm. J. Qual. Patient Saf. 2009, 35, 406-413. [CrossRef]

32. Arbune, A.; Wackerbarth, S.; Allison, P.; Conigliaro, J. Improvement through Small Cycles of Change: Lessons from an Academic Medical Center Emergency Department. J. Healthc. Qual. 2015, 39, 259-269. [CrossRef] [PubMed]

33. Kim, C.S.; Lukela, M.P.; Parekh, V.I.; Mangrulkar, R.S.; Del Valle, J.; Spahlinger, D.A.; Billi, J.E. Teaching internal medicine residents quality improvement and patient safety: A lean thinking approach. Am. J. Med. Qual. 2010, 25, 211-217. [CrossRef] [PubMed]

34. Weigel, C.; Suen, W.; Gupte, G. Using lean methodology to teach quality improvement to internal medicine residents at a safety net hospital. Am. J. Med. Qual. 2013, 28, 392-399. [CrossRef] 
35. Stelson, P.; Hille, J.; Eseonu, C.; Doolen, T. What drives continuous improvement project success in healthcare? Int. J. Health Care Qual. Assur. 2017, 30, 43-57. [CrossRef]

36. Hallam, C.R.A.; Contreras, C. Lean healthcare: Scale, scope and sustainability. Int. J. Health Care Qual. Assur. 2018, 31, 684-696. [CrossRef] [PubMed] 